\title{
Visit-to-visit blood pressure variability in different stages of chronic kidney disease
}

\author{
Alejandra A. Villagrasa-Flores' ${ }^{1}$, Jannice M. Arroyo-Soto ${ }^{1}$, Tatiana Rosado-Torres², Jesús D. Vega-Colón ${ }^{1 *}$, \\ Fátima Cintrón-Rosa ${ }^{1}$, Ángel F. Delgado-Garrastegui', Krystahl Z. Andújar-Rivera ${ }^{1}$, Eric Miranda-Valentín ${ }^{3}$, \\ Horacio Serrano-Rivera ${ }^{3}$, Ileana E. Ocasio-Meléndez ${ }^{1}$, and José L. Cangiano ${ }^{1}$ \\ ${ }^{1}$ Department of Internal Medicine, Nephrology Section, University of Puerto Rico, Medical Sciences Campus; ${ }^{2}$ Department of Biomedical Sciences, \\ Inter American University of Puerto Rico; ${ }^{3}$ Quantitative Proteomics Laboratory Translational Research, Comprehensive Cancer Center. San Juan, \\ Puerto Rico
}

\begin{abstract}
Introduction: Visit-to-visit variability (VVV) of blood pressure (BP) has been associated to cardiovascular mortality, stroke, and progression of chronic kidney disease (CKD). Objective: The objective of the study was to evaluate the association between VVV of BP and changes in estimated glomerular filtration rate (eGFR) in subjects with CKD Stage $3 A, 3 B$, and 4. Materials and methods: We analyzed the medical records of 75 CKD patients for a period of 48 months. Results: Demographic characteristics obtained revealed no differences between the three groups. The averages of the diastolic BP factor were 78.4, 74.7, and 76.5 for the CKD 3A, CKD 3B, and CKD 4, respectively. The greatest variability was observed in Stage 4 CKD with a value of $21.5 \%, 18.1 \%$, and $34.80 \%$ for eGFR, systolic BP (SBP), and pulse pressure (PP), respectively. The highest coefficient of variability was $34.80 \%$ in PP in Stage 4 CKD. In CKD 3A, eGFR is significantly associated with the PP factor. In CKD 3B, eGFR is significantly associated with the SBP factor and tends to significance with the PP factor. No significant association was found between the eGFR of stage CKD 4 and the different pressure factors. Conclusion: Our results demonstrated that if VVV of BP is not observed, eGFR would not be expected to decrease.
\end{abstract}

Key words: Blood pressure. Chronic disease. Glomerular filtration rate.

\section{Variabilidad de presión arterial de visita a otra en diferentes etapas de enfermedad renal crónica}

\section{Resumen}

Introducción: La variabilidad entre visita a visita (VVV) en la presión arterial (PA) está asociada a mortalidad cardiovascular, accidentes cerebrovasculares y la progresión de enfermedad renal crónica (ERC). Objetivo: Evaluar la asociación entre VVV en PA con los cambios en la tasa de filtración glomerular estimada (TFGe) en sujetos en estadios $3 A$, $3 B$ y 4 de ERC. Metodología: Analizamos los expedientes de 75 pacientes con ERC alrededor de 48 meses. Resultados: Las características demográficas no revelaron diferencias entre los tres grupos. La media de presión arterial diastólica (PAd) fue de 78.4, 74.7 y 76.5 para ERC estadio $3 A, 3 B$ y 4, respectivamente. La variabilidad más significativa observada fue en el estadio 4

Date of reception: 02-04-2021

*Jesús D. Vega Colón

Date of acceptance: 15-08-2021

DOI: 10.24875/NEFRO.21000010

E-mail: jesus.vega6@upr.edu

Disponible en internet: 27-12-2021

Nefro Latinoam. 2021;18:95-102 www.nefrologialatinoamericana.com

2444-9032/@ 2021Sociedad Latinoamericana de Nefrología e Hipertensión. Published by Permanyer. This is an open access article under the CC BY-NC-ND license (http://creativecommons.org/licenses/by-nc-nd/4.0/).
} 
Nefro Latinoam. 2021;18

con $21.5 \%, 18.8 \%$ y $34.80 \%$ para TFGe, presión arterial sistólica (PAs) y presión de pulso (PP), respectivamente. El coeficiente mayor de variabilidad observado (CV) fue de $34.80 \%$ para PP en el estadio 4. Se observó una asociación significativa entre la TFGe con la PAs en estadio CKD $3 B$ y una tendencia a significancia con la PP. No se apreció una asociación significativa entre la TFGe con las diferentes presiones en el estadio 4. Conclusión: Podemos esperar que la TFGe no disminuya si no se observa VVV en la PA.

Palabras clave: Presión arterial. Enfermedad crónica. Tasa de filtración glomerular.

\section{Introduction}

Hypertension is a well-established major risk factor for the development of cardiovascular disease and dea$t^{1}$. The prognostic value of blood pressure (BP) has been centered mainly on clinical readings typically obtained over several visits. The BP variability across visits has been traditionally dismissed as random fluctuations around a patient's true underlying BP. Nonetheless, Howard and Rothwell demonstrated that visit-to-visit intra-individual BP variability is reproducible instead of a random phenomenon ${ }^{2}$; setting the grounds for possible use of such variability as a prognostic indicator of cardiovascular and renal disease ${ }^{3,4}$.

Visit-to-visit variability (VVV) of BP has acquired great significance as a risk factor for cardiovascular events and death, independent of mean BP and on medication adherence ${ }^{5,6}$. In an early study, ambulatory BP measuring over a $24 \mathrm{~h}$ period revealed a high risk of left ventricular hypertrophy over a 7 year follow-up with a higher diurnal variability of $\mathrm{BP}^{7}$. Similarly, other studies have shown that VVV of BP conferred a higher risk for myocardial infarction and stroke ${ }^{8,9}$. Different methods have been proposed to evaluate VVV of BP, among these are standard deviation, coefficient of variation (CV), mean $\mathrm{BP}$, and continuous variable in ordinal fashion (ex. quintiles), and some investigators have suggested the use of systolic BP (SBP), diastolic BP (DBP), and pulse pressure (PP). Another consideration of importance in evaluating VVV of BP is the measurement of BP; automated, office, home; and the number of observations and different observers.

Numerous observations have been made trying to associate cardiovascular events to VVV of BP. Accordingly, in the NHANES study reported by Muntner et al., an increased all-cause mortality was associated to VVV of $\mathrm{BP}^{10}$. Based on this, and all the recent studies in large group of patients, the use of VVV of BP as a prognostic factor of vascular events has been clinically accepted within the medical community ${ }^{11,12}$.
A major interest is the relationship between VVV of BP and renal outcomes both in patients with and without pre-existing chronic kidney disease (CKD). Moreover, a higher BP variability was associated with new-onset CKD in patients with and without diabetes mellitus (DM), as evidenced by proteinuria and/or decline in the estimated glomerular filtration rate (eGFR) $^{13,14}$, while others have reported it to be a novel risk factor for the development and progression of diabetic nephropathy in diabetic patients without $C K D^{15-17}$. Further studies in diabetic patients have shown an association of such variability with the development of end-stage renal disease ${ }^{18,19}$. As a result of such myriad studies with diverse approaches, we evaluated the relationship between VVV of BP and changes in eGFR in three different stages of CKD in patients with or without diagnosis of DM and hypertension.

\section{Materials and Methods}

A retrospective cross-sectional analysis was made of the records of 75 patients at the CKD Clinic of the University Hospital. They were divided into three groups according to their renal function using the 4-variable Modification of Diet and Renal Disease (MDRD) formula and its progression was followed over a period of 4 years. Each group consisted of 25 patients; Group I included CKD Stage 3A (eGFR from 45 to $59 \mathrm{~mL} / \mathrm{min} / 1.73 \mathrm{~m}^{2}$ ), Group II with CKD Stage 3B (eGFR from 30 to 44), and Group III with CKD Stage 4 (eGFR from 15 to 29). Inclusion criteria consisted of adults ( $\geq 18$ years of age) with CKD Stage 3A, 3B, or 4. Exclusion criteria were those with CKD Stage 1, 2, or 5 , those with a history of malignancy or with nephrotic range proteinuria. Data collection was restricted to those with five consecutive visits. The data evaluated were demographic characteristics, medical history, BP measurement, antihypertensive treatment including angiotensin-converting enzyme inhibitors (ACEls), and angiotensin receptor blockers (ARB,), and renal function. The first five office visits measured were all used 
Table 1. Demographic characteristics of study participants by CKD stages $(n=75)$

\begin{tabular}{|c|c|c|c|}
\hline \multirow[t]{2}{*}{ Characteristics } & \multicolumn{3}{|c|}{ CKD stages } \\
\hline & CKD 3A $(n=25)$ & CKD 3B (n = 25) & CKD $4(n=25)$ \\
\hline Age (mean \pm SD) & $59.2 \pm 11.6$ & $59.4 \pm 14.4$ & $60.0 \pm 11.9$ \\
\hline $\begin{array}{l}\text { Sex } \\
\text { Men } \\
\text { Women }\end{array}$ & $\begin{array}{l}15(60.0) \\
10(40.0)\end{array}$ & $\begin{array}{l}14(56.0) \\
11(44.0)\end{array}$ & $\begin{array}{l}13(52.0) \\
12(48.0)\end{array}$ \\
\hline $\mathrm{BMI}, \mathrm{kg} / \mathrm{m}^{2}($ mean $\pm \mathrm{SD})$ & $29.2 \pm 7.1$ & $28.0 \pm 5.1$ & $28.7 \pm 7.9$ \\
\hline $\begin{array}{l}\text { History of DM, n (\%) } \\
\text { No } \\
\text { Yes }\end{array}$ & $\begin{array}{l}15(60.0) \\
10(40.0)\end{array}$ & $\begin{array}{l}15(60.0) \\
10(40.0)\end{array}$ & $\begin{array}{l}15(60.0) \\
10(40.0)\end{array}$ \\
\hline $\begin{array}{l}\text { History of hypertension, } \mathrm{n}(\%) \\
\text { No } \\
\text { Yes }\end{array}$ & $\begin{array}{c}7(28.0) \\
18(72.0)\end{array}$ & $\begin{array}{c}8(32.0) \\
17(68.0)\end{array}$ & $\begin{array}{c}9(36.0) \\
16(64.0)\end{array}$ \\
\hline
\end{tabular}

CKD: chronic kidney disease; BMI: basal metabolic index (kg/M²); DM: diabetes mellitus; SD: standard deviation.

to calculate variability, which is a reproducible approach. Demographic aspects included age, gender, height, weight, body mass index (BMI), history of DM and hypertension, baseline BP, and serum creatinine level. Our study was approved by the Institutional Review Board (A8660216) of the University of Puerto Rico, Medical Sciences Campus.

$\mathrm{BP}$ and heart rate measurements were made by trained nursing staff at the CKD clinics for a period of 48 months from January 2012 to December 2015. This was obtained with a standard calibration mercury sphygmomanometer and using an appropriate cuff for each patient. During each office visit, two consecutive readings were taken on the non-dominant arm with a 2 min interval after at least 5 min of rest in a sitting position. The average of the two readings was accepted as the office BP.

The mean office BP and the VVV of BP, expressed as intra-individual standard deviation (SD) and $\mathrm{CV}[\mathrm{CV}=\mathrm{SD} /$ mean office BP in the five visits $\times 100(\%)]$, were measured over the 48 months of observation with no $<5$ consecutive visits. Target BP was defined as $130 / 80 \mathrm{mmHg}$ or less as per guidelines of the Seventh Report of the Joint National Committee 7, the American Heart Association, and Kidney Disease Outcomes Qualitative Initiative ${ }^{20-22}$. Dietary sodium intake was restricted to $2 \mathrm{~g}$ of sodium daily and antihypertensive medications were given including ACEI, ARB, calcium channel blockers, and diuretics to control BP accordingly. The primary outcome was the rate of decline in renal function, estimated by fitting a regression line through the eGFR measurements at the beginning and at the end of the observation period. More than 30\% decrease in eGFR was categorized as significant.

Analyses were performed using STATA 14.0 program. Clinical characteristics were compared using Chi-square for categorical variables; ANOVA and Bonferroni tests for continuous variables. Linear regression analyses of the slope of the eGFR were performed. Spearman and Pearson correlation tests were also done.

\section{Results}

Demographic characteristics, including age, gender, and BMI of study participants by CKD stages in table 1 , showed no differences in the three groups studied. In table 2, we observed the averages with their respective standard deviations obtained from the different pressure factors studied (SBP, DBP, and PP) in the three stages of CKD (CKD 3A, CKD 3B, and CKD 4). The averages of the studied SBP factor were 135.9, 134.7, and 140.2 for the CKD 3A, CKD 3B, and CKD 4 stages, respectively, they were not significant. The averages of the DBP factor were 78.4, 74.7, and 76.5 for the CKD $3 \mathrm{~A}, \mathrm{CKD} 3 \mathrm{~B}$, and CKD 4 stages, respectively, they presented a trend towards significance $(p=0.056)$ in the difference of their variances when the three stages were compared. Similarly, the averages of the PP factor were 58.1, 60.0, and 63.75 for the CKD 3A, CKD 3B, and CKD 4 stages, respectively, presenting a trend toward significance $(p=0.068)$ in the difference of their variances compared to the different stages. The average PP factor increased from Stage CKD 3A to CKD 4. We can also find in table 2 the coefficient of variability 
Table 2. Means of clinical characteristics of study participants by CKD stages $(n=75)$, coefficient of variability of renal function (eGFR), and variability of renal function (eGFR) and BP readings with different CKD stages using Bonferroni test

\begin{tabular}{|c|c|c|c|c|}
\hline \multirow[t]{2}{*}{ Characteristics } & \multicolumn{3}{|c|}{ CKD stages } & \multirow[t]{2}{*}{ p-value } \\
\hline & CKD 3A (n = 25) & CKD 3B (n = 25) & CKD $4(n=25)$ & \\
\hline Mean eGFR $( \pm$ SD $)$ & $49.7 \pm 6.2$ & $36.3 \pm 3.6$ & $25.1 \pm 4.1$ & $<0.0001$ \\
\hline CV (\%) & 19.61 & 17.13 & 21.12 & \\
\hline $\begin{array}{l}\text { Bonferroni } \\
\text { CKD 3A versus CKD 3B } \\
\text { CKD 3A versus CKD } 4 \\
\text { CKD 3B versus CKD } 4\end{array}$ & $\begin{array}{l}- \\
-\end{array}$ & $\begin{array}{l}- \\
-\end{array}$ & $\begin{array}{l}- \\
- \\
-\end{array}$ & $\begin{array}{l}<0.0001 \\
<0.0001 \\
<0.0001\end{array}$ \\
\hline Mean SBP $( \pm$ SD $)$ & $135.9 \pm 20.0$ & $134.7 \pm 13.1$ & $140.2 \pm 19.8$ & 0.162 \\
\hline CV $(\%)$ & 17.41 & 14.30 & 18.16 & \\
\hline $\begin{array}{l}\text { Bonferroni } \\
\text { CKD 3A versus CKD 3B } \\
\text { CKD 3A versus CKD } 4 \\
\text { CKD 3B versus CKD } 4\end{array}$ & $\begin{array}{l}- \\
-\end{array}$ & $\begin{array}{l}- \\
-\end{array}$ & $\begin{array}{l}- \\
-\end{array}$ & $\begin{array}{l}1.000 \\
0.466 \\
0.208\end{array}$ \\
\hline Mean DBP $( \pm$ SD $)$ & $78.4 \pm 13.7$ & $74.7 \pm 10.5$ & $76.5 \pm 12.4$ & 0.056 \\
\hline CV $(\%)$ & 17.48 & 14.04 & 16.17 & \\
\hline $\begin{array}{l}\text { Bonferroni } \\
\text { CKD 3A versus CKD 3B } \\
\text { CKD 3A versus CKD } 4 \\
\text { CKD 3B versus CKD } 4\end{array}$ & $\begin{array}{l}- \\
- \\
-\end{array}$ & $\begin{array}{l}- \\
-\end{array}$ & $\begin{array}{l}- \\
-\end{array}$ & $\begin{array}{l}0.050 \\
0.610 \\
0.784\end{array}$ \\
\hline Mean PP $( \pm S D)$ & $58.1 \pm 14.2$ & $60.0 \pm 10.9$ & $63.7 \pm 16.6$ & 0.068 \\
\hline CV $(\%)$ & 30.93 & 27.97 & 34.80 & \\
\hline $\begin{array}{l}\text { Bonferroni } \\
\text { CKD 3A versus CKD 3B } \\
\text { CKD 3A versus CKD } 4 \\
\text { CKD 3B versus CKD } 4\end{array}$ & $\begin{array}{l}- \\
-\end{array}$ & $\begin{array}{l}- \\
-\end{array}$ & $\begin{array}{l}- \\
-\end{array}$ & $\begin{array}{l}1.000 \\
0.061 \\
0.401\end{array}$ \\
\hline
\end{tabular}

CKD: chronic kidney disease; eGFR: estimated glomerular filtration rate $\left(\mathrm{mL} / \mathrm{min} / 1.73 \mathrm{~m}^{2}\right)$; SBP: systolic blood pressure (mmHg); DBP: diastolic blood pressure (mmHg); PP: pulse pressure (mmHg); SD: standard deviation; CV: coefficient of variability; P value using ANOVA for continuous variables.

(CV) of eGFR, SBP, DBP, and PP. The greatest variability was observed in Stage 4 CKD with a value of $21.1 \%, 18.1 \%$, and $34.80 \%$ for eGFR, SBP, and PP, respectively. The highest CV was $34.80 \%$ in PP factor in Stage 4 CKD. The lowest CV was observed in the CKD 3B group in all different factors examined.

Bonferroni test was performed as a difference between CKD stages and was identified by ANOVA test on SBP, DBP, and PP. As shown on table 2, there is a significant difference on the variability of CKD $3 A$ and CKD 3B for DBP $(p=0.05)$. A tendency to significance $(p=0.061)$ was also observed in CKD $3 A$ and CKD 4 for PP. Finally, eGFR was significant in all stages of CKD $(p<0.0001)$.

Table 3 demonstrates the results of Spearman correlation tests for individual stages of CKD and Pearson test for total CKD. A significantly negative correlation was observed between eGFR and PP on CKD 3A (Rho $=-0.2477, p=0.005$ ). This signifies that on a lower eGFR, the value of PP is greater, or that as the eGFR increases the value of PP decreases. This observation is well shown in figure 1. A weak relation between eGFR and SBP was observed on CKD stage $3 B$ with $p=0.038$ and Rho 0.1861. In CKD 4 group, we observed a significant weak relation with SBP, DBP, and PP with $p$-values of $0.006,0.024$, and 0.054 , respectively, as observed in figures 1-3.

The association of clinical characteristics with eGFR by CKD stages is also observed in table 3 through the use of a linear regression mixed model. In CKD 3A, the eGFR is significantly associated with the PP factor ( $p=0.02$ ). In CKD 3B, the eGFR is significantly 
Table 3. Relation and association of BP readings with renal function (eGFR) by CKD and different CKD stages using Pearson, Spearman correlation, and linear regression mixed model tests

\begin{tabular}{|c|c|c|c|c|c|c|c|c|}
\hline \multirow[t]{2}{*}{ Characteristics } & \multicolumn{8}{|c|}{ CKD stages } \\
\hline & \multicolumn{2}{|c|}{ CKD $3 A(n=25)$} & \multicolumn{2}{|c|}{ CKD 3B (n = 25) } & \multicolumn{2}{|c|}{ CKD $4(n=25)$} & \multicolumn{2}{|c|}{ CKD (n = 75) } \\
\hline $\begin{array}{l}\text { Correlation } \\
\text { SBP } \\
\text { DBP } \\
\text { PP }\end{array}$ & $\begin{array}{c}\text { Rho } \\
-0.1646 \\
0.0419 \\
-0.2477\end{array}$ & $\begin{array}{c}\mathrm{p} \text {-value } \\
0.067 \\
0.643 \\
0.005\end{array}$ & $\begin{array}{c}\text { Rho } \\
0.1861 \\
0.1106 \\
0.1426\end{array}$ & $\begin{array}{c}\text { p-value } \\
0.038 \\
0.219 \\
0.113\end{array}$ & $\begin{array}{c}\text { Rho } \\
0.2476 \\
0.2031 \\
0.1736\end{array}$ & $\begin{array}{c}\mathrm{p} \text {-value } \\
0.006 \\
0.024 \\
0.054\end{array}$ & $\begin{array}{c}\text { Rho } \\
-0.0361 \\
0.1141 \\
-0.1058\end{array}$ & $\begin{array}{c}\mathrm{p} \text {-value } \\
0.486 \\
0.027 \\
0.041\end{array}$ \\
\hline $\begin{array}{l}\text { Association } \\
\text { SBP } \\
\text { DBP } \\
\text { PP }\end{array}$ & $\begin{array}{c}\beta \\
-0.05 \\
0.11 \\
-0.12\end{array}$ & $\begin{array}{c}\mathrm{p} \text {-value } \\
0.24 \\
0.15 \\
0.02\end{array}$ & $\begin{array}{c}\beta \\
0.07 \\
0.07 \\
0.06\end{array}$ & $\begin{array}{c}p \text {-value } \\
0.02 \\
0.19 \\
0.06\end{array}$ & $\begin{array}{c}\beta \\
0.03 \\
0.04 \\
0.02\end{array}$ & $\begin{array}{c}\mathrm{p} \text {-value } \\
0.15 \\
0.30 \\
0.29\end{array}$ & $\begin{array}{l}\beta \\
- \\
- \\
-\end{array}$ & $\begin{array}{c}\text { p-value } \\
- \\
- \\
-\end{array}$ \\
\hline
\end{tabular}

eGFR: estimated glomerular filtration rate $\left(\mathrm{mL} / \mathrm{min} / 1.73 \mathrm{~m}^{2}\right)$; BP: blood pressure $(\mathrm{mmHg})$; CKD: chronic kidney disease; SBP: systolic blood pressure (mmHg); DBP: diastolic blood pressure $(\mathrm{mmHg})$; PP: pulse pressure $(\mathrm{mmHg})$; $p$-values using Pearson and Spearman correlation test; $\mathrm{p}$-value using linear regression mixed models adjusted for the correlation of repeated measures; $\beta$-regression coefficient.

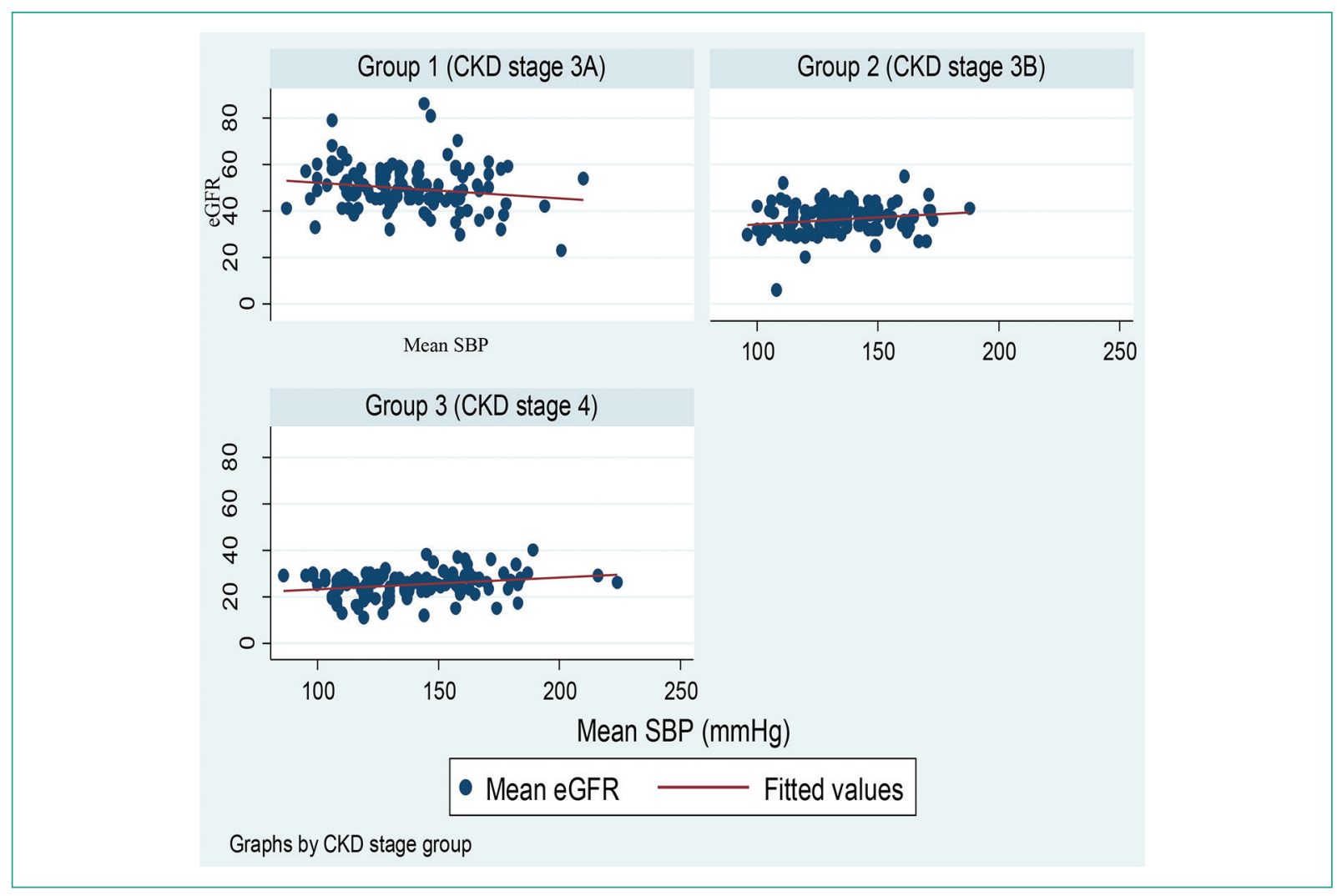

Figure 1. Simple correlations between eGFR and systolic blood pressure by CKD stages. eGFR: estimated glomerular filtration rate $\left(\mathrm{mL} / \mathrm{min} / 1.73 \mathrm{~m}^{2}\right)$; SBP: systolic blood pressure $(\mathrm{mmHg})$; CKD: chronic kidney disease.

associated with the SBP factor $(p=0.02)$ and tends to significance with the PP factor $(p=0.06)$. No significant association was observed between the eGFR of Stage CKD 4 and the different pressure factors.

\section{Discussion}

To the best of our knowledge, this is the first study that explores the VVV of BP in separate groups of CKD patients according to renal function for 48 months. Our 


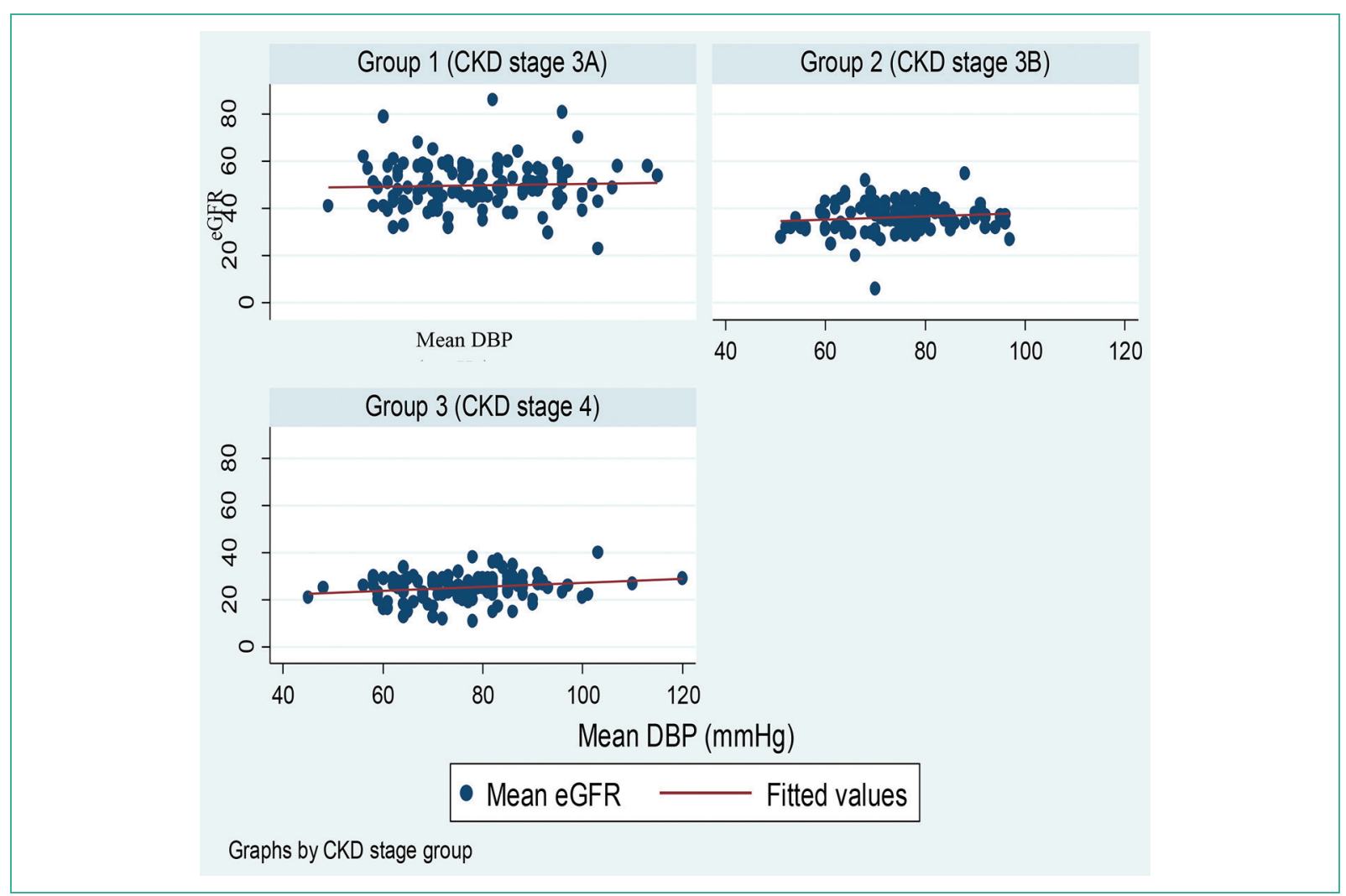

Figure 2. Simple correlations between eGFR and systolic blood pressure by CKD stages. eGFR: estimated glomerular filtration rate $\left(\mathrm{mL} / \mathrm{min} / 1.73 \mathrm{~m}^{2}\right)$; SBP: systolic blood pressure $(\mathrm{mmHg})$; CKD: chronic kidney disease.

study showed no statistically significant VVV of BP in any of the CKD groups. We did observe a trend toward significance in VVV for SBP and PP in CKD Stage 4. This may be explained by known increased prevalence of hypertension with advanced CKD stages. VVV of SBP did not result in a decrease on renal function in CKD $3 B$ and CKD 4, while in CKD 3A, it was associated with a non-statistically significant decline in renal function. VVV of PP exhibited a similar pattern with a weak correlation observed in all stages of CKD with a tendency for significance. It is noteworthy that even there were no significant changes in the ages of our studied population, the mean PP was increased along the three stages analyzed. This may be associated to an increased vascular calcification as reported in advancing CKD stages ${ }^{23,24}$. Other studies have emphasized the association of pulse wave velocity and decline in renal function in $\mathrm{CKD}^{25,26}$. Zhang et al. observed a significant association between increased VVV of SBP and PP with the measurement of pulse wave velocity ${ }^{27}$.

Our results demonstrated that if VVV of BP is not observed, the eGFR would not be expected to decrease. These observations are in accordance with the study of Yokota et al. in 69 diabetic CKD patients, without analyzing separately the stages of CKD, which demonstrated no decline in renal function with VVV of $\mathrm{BP}$ using the MDRD formula to measure eGFR ${ }^{28}$. On the other hand, Lasserson et al., in a 5-year retrospective cohort study of a spectrum of CKD patients, showed worsening of renal function associated to small increases of VVV of BP using CKD-EPI formula to measure eGFR ${ }^{29}$. These differences raised the question of the method used for calculating the eGFR and the outcome. We believe that the use of antihypertensive medications conferred a beneficial effect as demonstrated by a stable VVV of BP in all three groups of CKD patients. This is in accordance with other studies, Zhang et al., Rothwell et al., and Wang et al. who have demonstrated that such antihypertensive medications ameliorate the VVV of BP and subsequently blunting renal function decline ${ }^{30-32}$.

Other studies have looked into renal variables, one example is a retrospective cohort study of 354 participants who demonstrated that CV of SBP was positively 


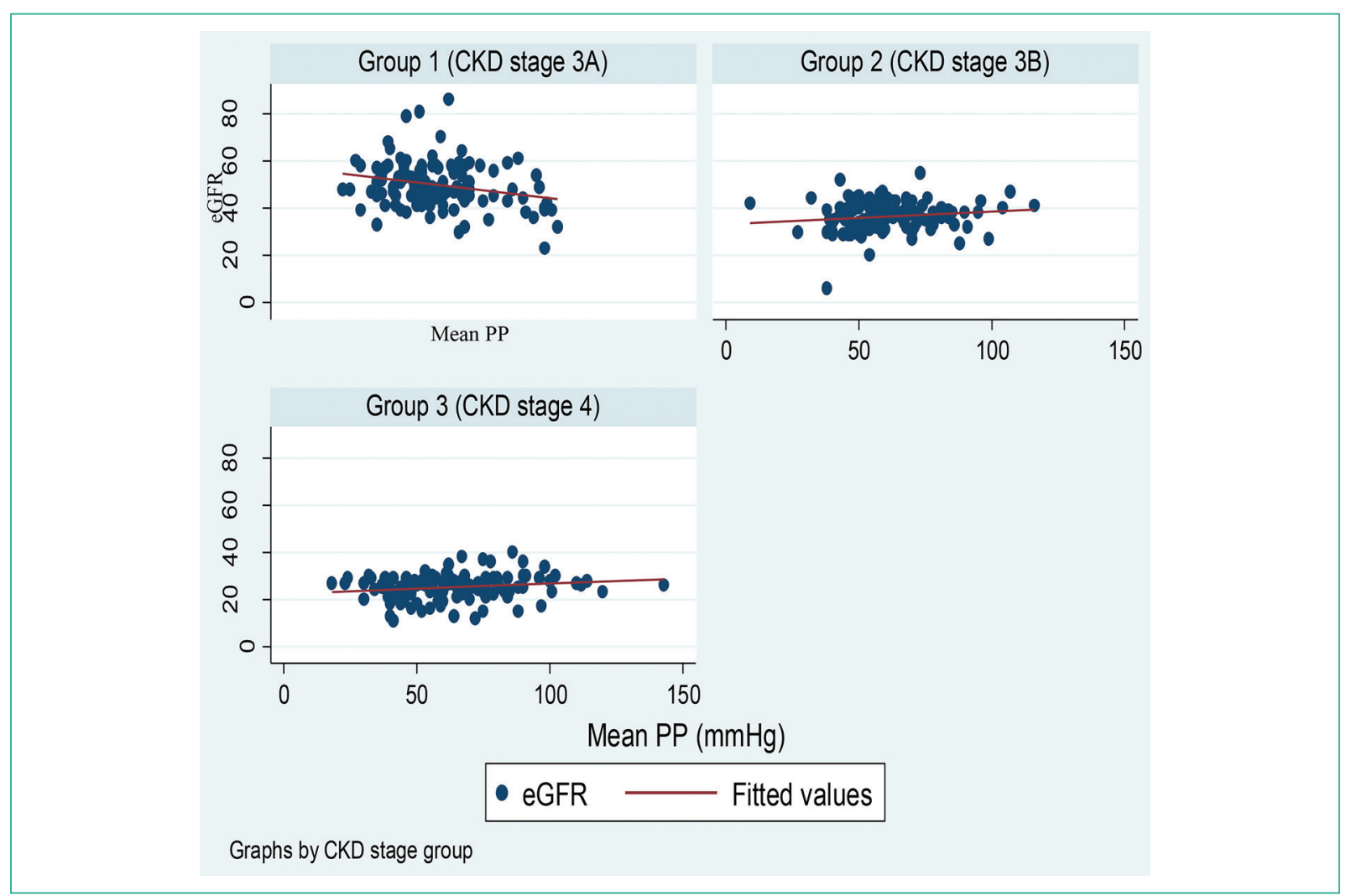

Figure 3. Simple correlations between eGFR and diastolic blood pressure by CKD stages. eGFR: estimated glomerular filtration rate $\left(\mathrm{mL} / \mathrm{min} / 1.73 \mathrm{~m}^{2}\right)$; DBP: diastolic blood pressure $(\mathrm{mmHg})$; CKD: chronic kidney disease.

correlated with age, duration of diabetes, and change in urinary albumin excretion ${ }^{33}$. The post hoc analysis from the RENAAL study and the Irbesartan Diabetic Nephropathy trial (multi-national, double blind, randomized placebo controlled) by McMullan et al. demonstrated significant increased risk in renal end points with SBP $>140 \mathrm{mmHg}$ and PP $>70 \mathrm{mmHg}$. The adjusted risk for end-stage renal disease or death increased with a hazard ratio of $1.96(1.40-2.74)^{34}$. It has been also proposed by the Trophy study (Trial of Preventing Hypertension) that the number, timing of visits, device used to measure BP influence VVV and needs to be considered when designing, interpreting, and comparing studies ${ }^{35}$. Furthermore, Wang et al. using $24 \mathrm{~h}$ ambulatory recordings in hospitalized elderly male patients with controlled $\mathrm{BP}$, demonstrated the association of $24 \mathrm{~h}$ SBP variability and a decline in renal function after adjustment with potential confounding factors. Nonetheless, they also performed studies in elderly population with three different stages of renal function expressed by eGFR in $\mathrm{mL} / \mathrm{min} / 1.73 \mathrm{~m}^{2}$ : $>90,60-89$, and $<60$ group showing no significant changes among the three groups in the SBP and DBP variability ${ }^{32}$.
Potential limiting factors in our study were small sample size, as well as home BP measurements were not determined, which may be another important factor in considering VVV of BP.

\section{Conclusion}

Our study presents a novel approach in determining how VVV of BP affects the eGFR at specific stages of CKD, in patients with and without diagnosis of DM. It will be of great interest to document VVV of BP in CKD Stages 1, 2, and 5 (non-dialysis patients). We recommend future studies to discern the value of VVV of BP in CKD.

\section{Acknowledgments}

The authors would like to acknowledge Marievelisse Soto Salgado, DrPH, M.S. (UPR/MDACC Partnership for Excellence in Cancer Research, University of Puerto Rico, Medical Sciences Campus, marievelisse. soto1@upr.edu). 


\section{Conflicts of interest}

The authors declare that they do not present any type of conflicts of interest that may affect the results and content in relation to this publication.

\section{Funding}

The research project did not receive specific funding.

\section{Ethical disclosures}

Protection of human and animal subjects. The authors declare that no experiments were performed on humans or animals for this study.

Confidentiality of data. The authors declare that they have followed the protocols of their work center on the publication of patient data.

Right to privacy and informed consent. The authors declare that no patient data appear in this article.

\section{References}

1. Young JH, Klag MJ, Muntner P, Whyte JL, Pahor M, Coresh J, et al. Blood pressure and decline in kidney function: findings from the Systolic Hypertension in the Elderly Program (SHEP). J Am Soc Nephrol. 2002;13:2776-82.

2. Howard SC, Rothwell PM. Reproducibility of measures of visit-to-visit variability in blood pressure after transient ischemic attack or minor stroke. Cerebrovasc Dis. 2009;28:331-40.

3. MacMahon S, Peto R, Cutler J, Collins R, Sorlie P, Neaton J, et al. Blood pressure, stroke, and coronary heart disease. Part 1, Prolonged differences in blood pressure: prospective observational studies corrected for the regression dilution bias. Lancet. 1990;335:765-74

4. Muntner P, Joyce C, Levitan EB, Holt E, Shimbo D, Webber LS, et al. Reproducibility of visit-to-visit variability of blood pressure measured as part of routine clinical care. J Hypertens. 2011;29:2332-8.

5. Parati G, Pomidossi G, Albini F, Malaspina D, Mancia G. Relationship of 24-hour blood pressure mean and variability to severity of target-organ damage in hypertension. J Hypertens. 1987:5:93-8.

6. Muntner P, Levitan EB, Joyce C, Holt E, Mann D, Oparil S, et al. Association between antihypertensive medication adherence and visit-to-visit variability of blood pressure J Clin Hypertens. 2013:15:112-7.

7. Frattola A, Parati G, Cuspidi C, Albini F, Mancia G. Prognostic value of 24-hour blood pressure variability. J Hypertens. 1993;11:1133-7.

8. Hata $\mathrm{Y}$, Muratani $\mathrm{H}$, Kimura $\mathrm{Y}$, Fukiyama K, Kawano $\mathrm{Y}$, Ashida $\mathrm{T}$, et al. Office blood pressure variability as a predictor of acute myocardial infarction in elderly patients receiving antihypertensive therapy. J Hum Hypertens. 2002:16:141-6.

9. Hata Y, Kimura Y, Muratani H, Fukiyama K, Kawano Y, Ashida T, et al Office blood pressure variability as a predictor of brain infarction in elderly hypertensive patients. Hypertens Res. 2000;23:553-60.

10. Muntner $P$, Shimbo D, Tonelli M, Reynolds K, Arnett DK, Oparil S. The relationship between visit-to-visit variability in systolic blood pressure and all-cause mortality in the general population: findings from NHANES III, 1988 to 1994 . Hypertension. 2011;57:160-6.

11. Brickman AM, Reitz C, Luchsinger JA, Manly JJ, Schupf N, Muraskin J, et al. Long-term blood pressure fluctuation and cerebrovascular disease in an elderly cohort. Arch Neurol. 2010;67:564-9.

12. Rothwell PM. Limitations of the usual blood-pressure hypothesis and importance of variability, instability, and episodic hypertension. Lancet. 2010;375:938-48

13. Mancia G, Facchetti R, Parati G, Zanchetti A. Visit-to-visit blood pressure variability in the European lacidipine study on atherosclerosis: methodological aspects and effects of antihypertensive treatment. J Hypertens. 2012;30:1241-51.
14. $Y$ ano $Y$, Fujimoto $S$, Kramer $H$, Sato $Y$, Konta $T$, Iseki $K$, et al. Long-term blood pressure variability, new-onset diabetes mellitus, and new-onset chronic kidney disease in the Japanese general population. Hypertension. 2015;66:30-6

15. Yokota K, Fukuda M, Matsui Y, Hoshide S, Shimada K, Kario K. Impact of visit-to-visit variability of blood pressure on deterioration of renal function in patients with non-diabetic chronic kidney disease. Hypertens Res. 2013;36:151-7.

16. Di lorio B, Pota A, Sirico ML, Torraca S, Di Micco L, Rubino R, et al. Blood pressure variability and outcomes in chronic kidney disease. Nephrol Dial Transplant. 2012:27:4404-10.

17. Hata J, Arima H, Rothwell PM, Woodward M, Zoungas S, Anderson C, et al, ADVANCE Collaborative Group. Effects of visit-to-visit variability in systolic blood pressure on macrovascular and microvascular complications in patients with type 2 diabetes mellitus: the ADVANCE trial. Circulation. 2013;128:1325-34

18. Rothwell PM, Howard SC, Dolan E, O'Brien E, Dobson JE, Dahlöf B, et al. Prognostic significance of visit-to-visit variability, maximum systolic blood pressure, and episodic hypertension. Lancet. 2010;375:895-905.

19. Whittle J, Lynch Al, Tanner RM, Simpson LM, Davis BR, Rahman M, et al. Visit-to-visit variability of blood pressure and chronic kidney disease outcomes: results from the ALLHAT. Clin J Am Soc Nephrol. 2016;11:471-80.

20. Chobanian AV, Bakris GL, Black HR, Cushman WC, Green LA Izzo JL Jr., et al. The seventh report of the joint national committee on prevention, detection, evaluation, and treatment of high blood pressure: the JNC 7 report. JAMA. 2003;289:2560-72.

21. Rosendorff $C$. Hypertension and coronary artery disease: a summary of the American heart association scientific statement. J Clin Hypertens. 2007;9:790-5.

22. Kidney Disease Outcomes Quality Initiative (K/DOQI). K/DOQI clinical practice guidelines on hypertension and antihypertensive agents in chronic kidney disease. Am J Kidney Dis. 2004;43:S1-290.

23. Goodman WG, Goldin J, Kuizon BD, Yoon C, Gales B, Sider D, et al. Coronary artery calcification in young adults with end stage renal disease who are undergoing dialysis. N Eng J Med. 2000;342:1478-83.

24. Gusbeth-Tatomir P, Covic A. Causes and consequences of increased arterial stiffness in chronic kidney disease patients. Kidney Blood Press Res. 2007;30:91-107.

25. Weber T, Ammer M, Gündüz D, Bruckenberger $\mathrm{P}$, Eber B, Wallner $\mathrm{M}$. Association of increased arterial wave reflections with decline in renal function in chronic kidney disease stages III and IV. Am J Hypertens. 2011;24:762-9.

26. Townsend RR, Anderson AH, Chirinos JA, Feldman HI, Grunwald JE, Nessel L, et al. Association of pulse wave velocity with chronic kidney disease progression and mortality. Findings from the CRIC study. Hypertension. 2018:71:1101-7.

27. Zhang Y, Bie L, Mian L, Wang T, Xu M, Lu J, et al. Visit to visit blood pressure variability is associated with arterial stiffness in Chinese adults: a prospective analysis. J Clin Hypertens. 2021;23:802-12.

28. Yokota K, Fukuda M, Matsui Y, Kario K, Kimura K. Visit-to-visit variability of blood pressure and renal function decline in patients with diabetic chronic kidney disease. J Clin Hypertens. 2014;16:362-6.

29. Lasserson $D$, Sherpbier de Haan $N$, van der Wel M, de Grauw W, Wetzels JF, O'Callaghan CA. What is the relationship between renal function and visit-to-visit blood pressure variability in primary care? Retrospective cohort study from routinely collected healthcare data. BMJ Open. 2016;6:1-6.

30. Zhang Y, Agnoletti D, Safar ME, Blacher J. Effect of antihypertensive agents on blood pressure variability: the Natrilix SR versus candesartan and amlodipine in the reduction of systolic blood pressure in hypertensive patients (X-CELLENT) study. Hypertension. 2011;58:155-60.

31. Rothwell PM, Howard SC, Dolan E, O'Brien E, Dobson JE, Dahlöf B, et al. Effects of beta blockers and calcium-channel blockers on withinindividual variability in blood pressure and risk of stroke. Lancet Neurol. 2010:9:469-80.

32. Wang X, Wang F, Chen M, Wang X, Zheng J, Qin A. Twenty-four-hour systolic blood pressure variability and renal function decline in elderly male hypertensive patients with well-controlled blood pressure. Clin Interv Aging. 2018:13;533-40.

33. Okada H, Fukui M, Tanaka M, Matsumoto S, Mineoka Y, Nakanishi N, et al. Visit-to-visit blood pressure variability is a novel risk factor for the developments and progression of diabetic nephropathy in patients with type 2 diabetes. Diabetes Care. 2013;36:1908-12.

34. McMullan CJ, Lambers Heerspink HJ, Parving HH, Dwyer JP, Forman JP, de Zeeuw D, et al. Visit-to-visit variability in blood pressure and kidney and cardiovascular outcomes in patients with type 2 diabetes and nephropathy: a post hoc analysis from the RENAAL study and the Irbesartan diabetic nephropathy trial. Am J Kidney Dis. 2014;64:714-22.

35. Levitan EB, Kaciroti N, Oparil S, Julius S, Muntner P. Blood pressure measurement device, number and timing of visits, and intra-individual visit-to-visit variability of blood pressure. Clin Hypertens. 2012:14:744-50. 